\title{
A Case Study of a Regional Torrential Rain in North China Caused by Typhoon Damrey (2012)
}

\author{
Rui Xing1, Yuejia Zhu' ${ }^{2 *}$, Chengcheng Feng ${ }^{3}$ \\ ${ }^{1}$ Tianjin Binhai New District Meteorological Bureau, Tianjin, China \\ ${ }^{2}$ Anhui Meteorological Observatory, Hefei, China \\ ${ }^{3}$ Dalian Meteorological Observatory, Dalian, China \\ Email: *zxk668@126.com
}

How to cite this paper: Xing, R., Zhu, Y.J. and Feng, C.C. (2018) A Case Study of a Regional Torrential Rain in North China Caused by Typhoon Damrey (2012). Journal of Geoscience and Environment Protection, 6, 220-227.

https://doi.org/10.4236/gep.2018.65018

Received: November 30, 2017

Accepted: May 27, 2018

Published: May 30, 2018

Copyright $\odot 2018$ by author and Scientific Research Publishing Inc. This work is licensed under the Creative Commons Attribution International License (CC BY 4.0).

http://creativecommons.org/licenses/by/4.0/

(c) (i) Open Access

\begin{abstract}
By using the NCEP/GFS analysis data, CIMISS data, JMA and China's Typhoon Networks, heavy rainstorm occurred in east of North China associated with Typhoon Damrey from August 3rd to 4th, 2012 was analyzed. Results show during Damrey was going nearby Tianjin City and Hebei province of China, heavy rainstorm was observed in the cities of Qinhuangdao and Tangshan. The southerly jet stream from the southern side of the subtropical high and the periphery of Typhoon Saola is the conveyor belt for water vapor and energy, which enables Damrey to maintain for a long time and provide water vapor and heat conditions for rainfall in east of North China. The structure of Damrey caused a strong updraft in east of North China with a K-index greater than $35^{\circ} \mathrm{C}$, which provided a favorable condition for the heavy rainstorm. The typhoon rainstorms in North China are the result of the interaction of the westerly, subtropical and tropical systems. In this heavy rain period, there was an obvious interaction between subtropical and tropical systems. This study has investigated the interaction between the northwestern Pacific typhoon and the North China heavy rainstorm, including the circulation characteristics of the typhoon and North China before and after the regional heavy rainstorm. Additionally, the climate background provides a reliable basis for the heavy rain forecast.
\end{abstract}

\section{Keywords}

Typhoon Damrey, Rainstorm in North China, Synoptic System Interaction

\section{Introduction}

A typhoon is a mature tropical cyclone that develops in the Northwestern Pacific 
Basin, which is the most active tropical cyclone basin on Earth, accounting for almost one-third of the world's annual tropical cyclones, which bring winds and rainstorms to Asia countries like China [1] [2] [3]. However, a typhoon differs from a cyclone or hurricane only on the basis of location, while hurricane is a storm that occurs in the Atlantic Ocean and northeastern Pacific Ocean, a typhoon occurs in the northwestern Pacific Ocean, and a cyclone occurs in the south Pacific or Indian Ocean.

Typhoons always bring heavy rain to the southern provinces of China according to the local meteorological authority's research. It is concluded that the reason of frequent flooding in the Zhujiang Valley is due to both natural factors such as torrential rain and typhoon rainstorm, also effecting by typhoon and rainstorm, in one of the highways of Zhejiang, China occurred geological hazard [4]. Other research shows that typhoons also bring heavy rains to North China, and a large numbers of statistical calculations of typhoon rainstorm from 1949 to 2000 show that the decade difference of typhoon rainstorm was very remarkable [5]. A typical case is that Typhoon No. 9608 made continuous great rainstorm and exceptional rainstorm in south area of Hebei province, China on August 3 and 4, 1996 and caused very serious economic and personal loss [6]. This may because that typhoon rainstorm has relation to the dissymmetry of typhoon circulation fields and heat fields, but does not always close to the center of circulation [7].

When the factors appear entirely at station of precipitation cloud area of typhoon, heavy rainstorm is easy to occur. Typhoon No. 10 in 2012, which named "Damrey", is the strongest typhoon that landed in the area north of the Yangtze River in China since 1949 till 2012. Despite its impact, the Cities of Tangshan and Qinhuangdao in Hebei Province, which is located in east of North China, despite the rare heavy rains, caused a very serious economic loss. This shows that it is very urgent and necessary to intensify the study of typhoons passed nearby North China. At the same time, with the development of the means of atmospheric exploration and the application of new information, we can understand the characteristics and formation mechanism of typhoon torrents in more detail and accumulate new experiences for improving the forecaster's forecasting ability.

\section{Data and Methods}

\subsection{Data Gathered}

First, the Global Forecast System (GFS) is a weather forecast model produced by the National Centers for Environmental Prediction (NCEP) [8] [9] [10]. Dozens of atmospheric and land-soil variables are available through this dataset, from temperatures, winds, and precipitation to soil moisture and atmospheric ozone concentration. The entire globe is covered by the GFS at a base horizontal resolution of $0.5^{\circ}$ between grid points. Gridded data are available for download through the NOAA National Operational Model Archive and Distribution System (NOMADS). We use only its analysis data to plot weather charts and calculate physical diagnoses. 
Then, China Integrated Meteorological Information Sharing System (CIMISS) is developed by National Meteorological Information Center of China Meteorological Administration [11]. CIMISS is designed for undertaking a series of operations of meteorological data collecting, processing, storage, retrieval and dissemination. Data cover all real time and historical meteorological observations and products, including 14 classes that are surface, upper-air, solar radiation, oceanic meteorology, agro-meteorology, radar, satellite, proxy climate, atmospheric chemistry, numeric model analysis and forecast, scientific experiment, meteorological disaster, meteorological service product and the others. Data cover the geographic area from China to global, and the period from 1951 to now. Real-time data come from all kind of meteorological observation networks in China and Users can access the data by Web page and by application programming interface (API). Through it, we downloaded conventional and density-enhanced automatic weather station observations for research.

Some charts from Japan Meteorological Agency (JMA) and China's Typhoon Networks were also used.

\subsection{Methodology}

We used Grid Application Development Software (GrADS) [12] project which is one of the useful programming tools and an execution environment to ease program development for the grid to plot weather charts and other diagnosis charts.

\section{Results and Analysis}

\subsection{Typhoon Damrey and the Rainstorm}

Damrey developed into a tropical storm north of the Tropic of Cancer on July 28th, 2012 and drifted slowly. By late on July 30th, Damrey began to accelerate west-northwestward, with a high generate latitude, strong and small scale, formed a double typhoon effect with the Typhoon Saola (No. 1209) in south. The storm struggled to make deep convection wrap around itself due to vertical wind shear and dry air since formation, until it passed near Kyushu on August 1st. Damrey finally intensified into a typhoon early on August 2nd, a half of day before it made landfall over over Xiangshui County in Jiangsu, China at 13:30 UTC [13]. Then the system went through Jiangsu, Shandong and Hebei provinces of China and finally dissipated near the coast of Qinhuangdao City in Hebei Province on August 4th, 2012. Figure 1 shows the typhoon path archived from the Japan Meteorological Agency.

The precipitation brought by Damrey to North China mainly occurred at 00:00 UTC on August 3rd and 00:00 UTC on August 4th. During this period, precipitation was found in many parts, more accurately, accounting for more than $80 \%$ of all observatories in Tianjin City and Hebei Province which are located in the eastern part of North China (Figure 2). Influenced by Damrey and its peripheral circulation, heavy rain mainly affected in the cities of Qinhuangdao and Tangshan. The rainfall above the heavy rainstorm was observed 


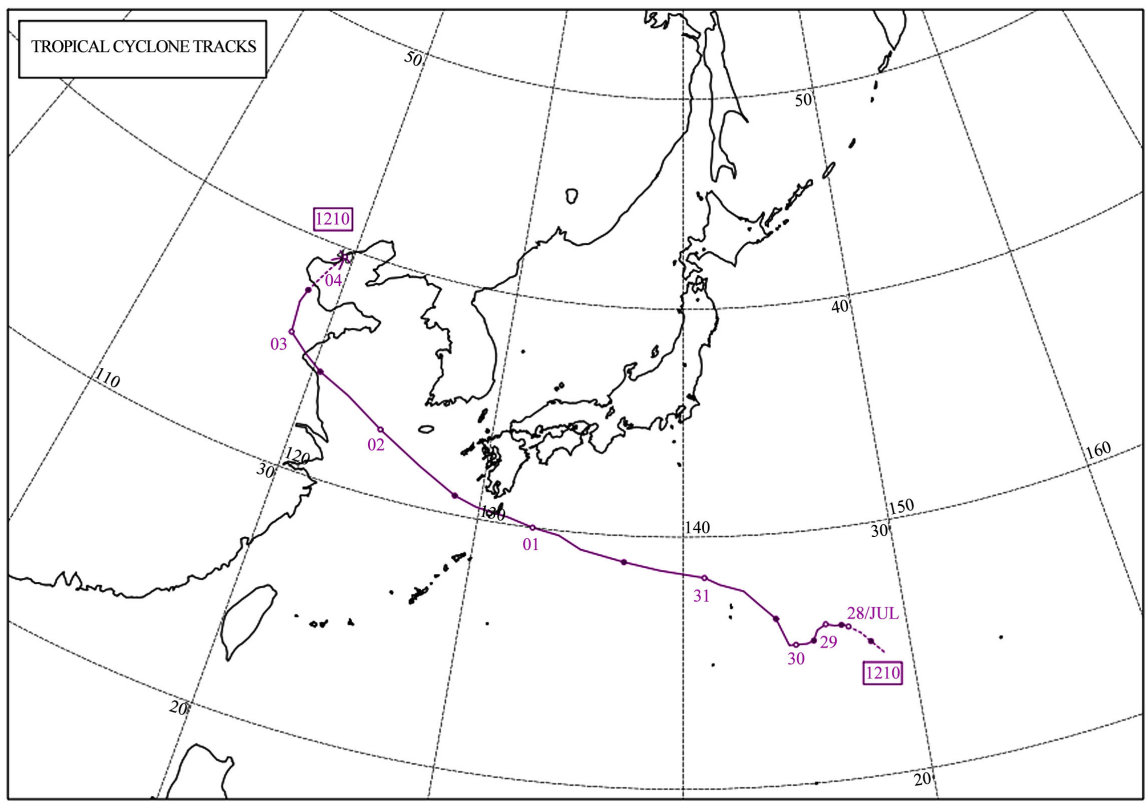

Figure 1. Typhoon Damrey's track from JMA, available at: http://www.data.jma.go.jp/fcd/yoho/data/typhoon/T1210.png

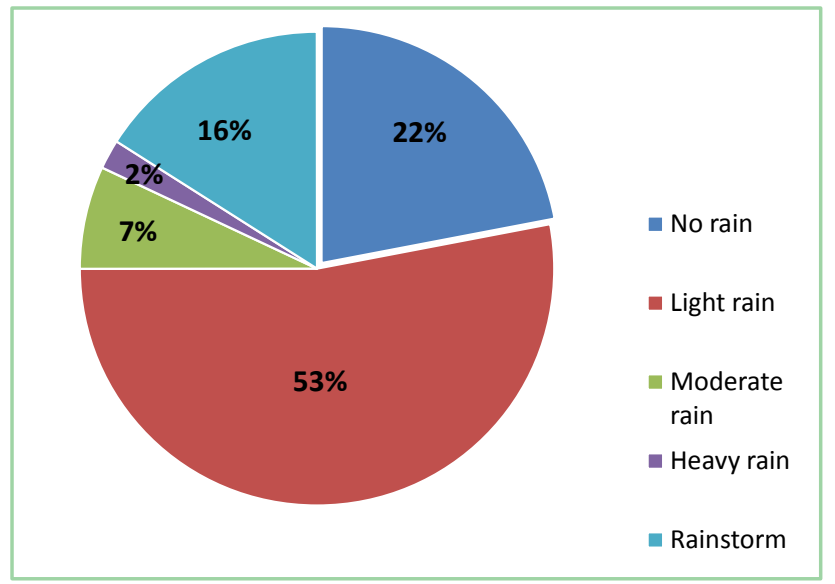

Figure 2. Rainfall distribution of observatories in Tianjin City and Hebei Province, China during 00:00 UTC on August 3 and 00:00 UTC on August 4, 2012.

at 158 observatories in Tianjin City and Hebei Province, with a maximum of $306.5 \mathrm{~mm}$ in Haiyang Observatory of Qinhuangdao City and followed $273.3 \mathrm{~mm}$ in Tangjiahe Observatory of Tangshan City. The automatic weather stations in the coastal area of Bohai Sea showed that the average wind power reached levels 8 - 9 with a maximum wind speed of $27 \mathrm{~m} / \mathrm{s}$ (level 10) and the highest tide level also exceeded the warning level. The bad weather coincided with the astronomical tide on the 15th of the lunar calendar, mixed wind, rain and tide.

\subsection{Circulations}

At 00:00 UTC on August 3rd, there were two troughs and one ridge in the mid- 
dle and high latitudes at $500 \mathrm{hPa}$ high altitude (Figure 3(a)). There is also a short wave trough moving eastward in the Hetao area. The subtropical high is massive, its ridge line is stable near $37^{\circ} \mathrm{N}$ and the west pole is in the Liaodong Peninsula. Damrey is located on the west side of the subtropical high, slightly southward, and then gradually migrates to the north-northwest with the subtropical peripheral south-easterly airstream. At the same time, another strong tropical storm, Saola, is located at the junction of Fujian and Zhejiang Provinces' coastal areas, with the southeast periphery of the subtropical high current to the northwest. At 12:00 UTC on August 3, the upstream westerly trough moved northeastward and the center of the subtropical high shifted slightly westward (Figure $3(\mathrm{~b})$ ). The ridge line of the subtropical high retreated to south at $35^{\circ} \mathrm{N}$ and west pole extended to the junction zone between Shandong and Jiangsu provinces. Damrey weakened into a tropical storm and located in the northwestern quadrant of the subtropical high, indicating that Damrey turned northeastward and northward. The cities of Qinhuangdao and Tangshan are located on the northern side of the typhoon with a stronger easterly wind and a clear convergence of the current and significant precipitation enhancement.

In the figure, the blue line indicates the contour line and the red line indicates the isotherm.

\subsection{Vapor, Energy and Dynamic Conditions}

By using the NCEP/GFS analysis data to calculate the water vapor flux divergence at $850 \mathrm{hPa}$, we can see that the southeast periphery of the subtropical high and the southerly flows from the strong tropical storm Saola formed a southeast wind jet, which delivered a steady flow of water vapor from the sea to Damrey and produced a strong water vapor flux convergence in the east of North China, contributing to the occurrence of heavy rainfall (Figure 4(a)). Sufficient water vapor supply provided the water vapor conditions for the rainstorm areas, at the same time, the release of latent heat of condensation fuelled the system and enabled it to last long. According to the NCEP temperature advection at $500 \mathrm{hPa}$ in 06:00 UTC on August 3rd (Figure 4(b)), we can see that there are large value centers for the temperature over the dimensions of both Damrey and Sula. The two centers were connected to each other, and there was an interaction between them so that Damrey can maintain it. Affected by the Damrey periphery, it was warm and wet at $500 \mathrm{hPa}$ in east of North China, and the strong precipitation occurred on the warm and wet side of the temperature gradient.

When the water vapor conditions and energy conditions are met, the dynamic conditions are triggered by the unstable stratification, triggering the rising movement of precipitation necessary conditions. At 18:00 UTC on the August $3 \mathrm{rd}$, the wind distribution of $850 \mathrm{hPa}$ (Figure 5(a)) shows that there is convergence of the southerly and northerly winds in east of North China. It is the convergence zone of the wind speed and the upward movement zone. The ascending speed reached $2 \mathrm{~Pa} / \mathrm{s}$ just like July 21st heavy rain in 2012 in Beijing [14]. The 


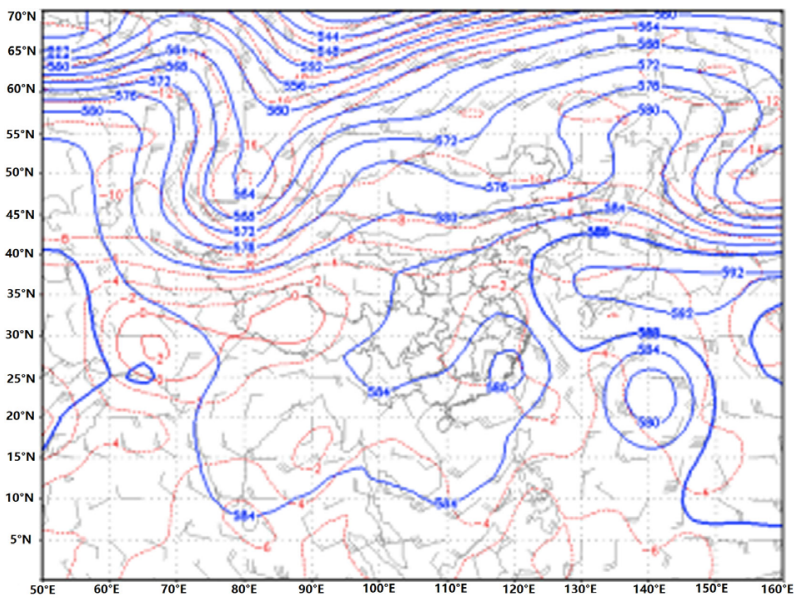

(a)

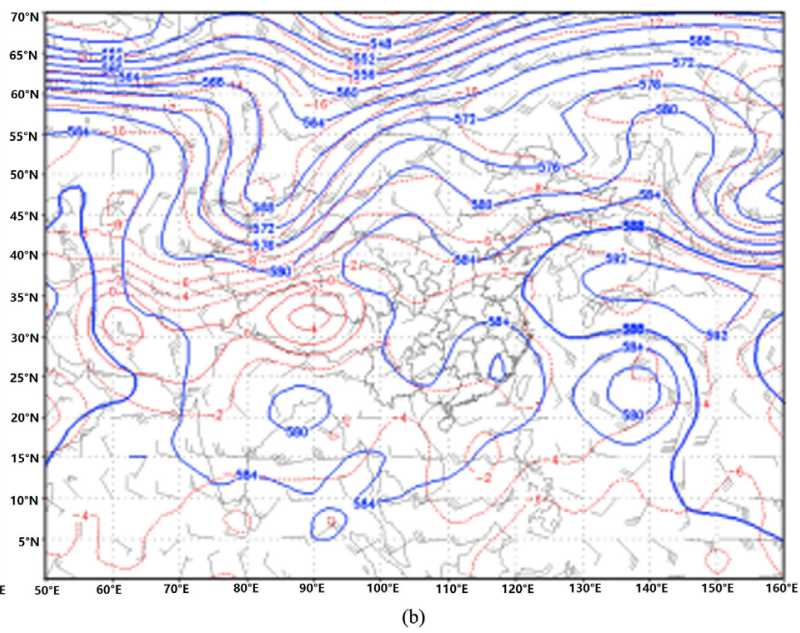

(b)

Figure 3. Synoptic chats at $500 \mathrm{hPa}$ at (a) 00:00 UTC and (b) 12:00 UTC on August 3, 2012.

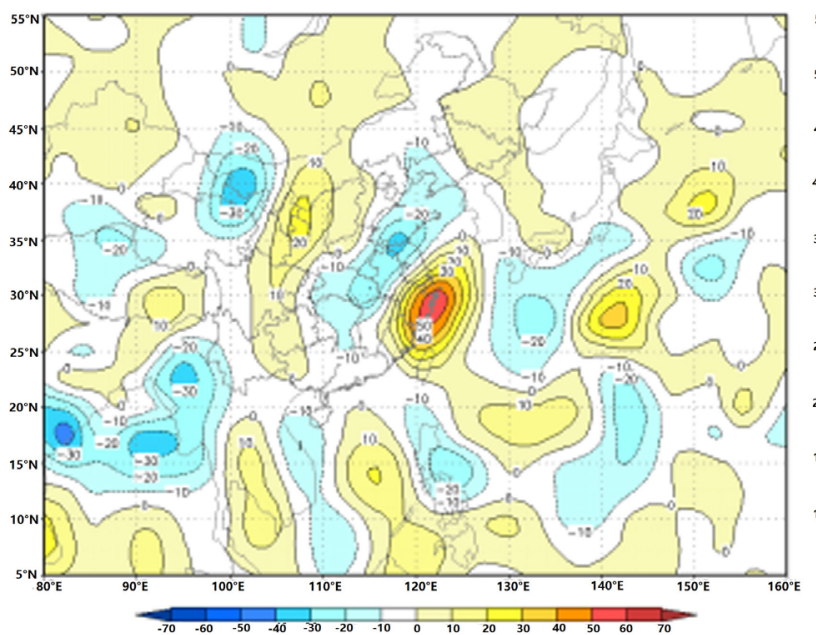

(a)

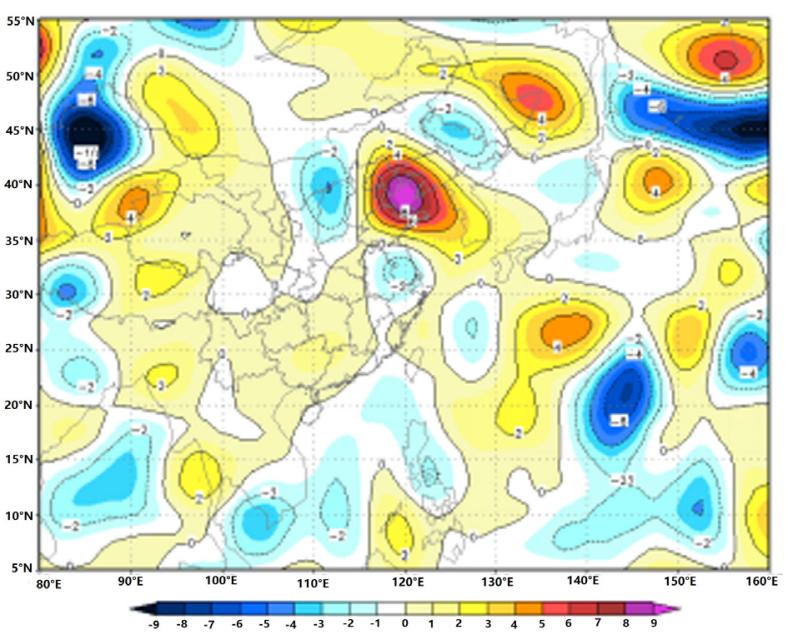

(b)

Figure 4. (a) Water vapor flux divergence at $850 \mathrm{hPa}$ at 18:00 UTC and (b) Temperature advection at 500 hPa at 06:00 UTC on August 3, 2012.
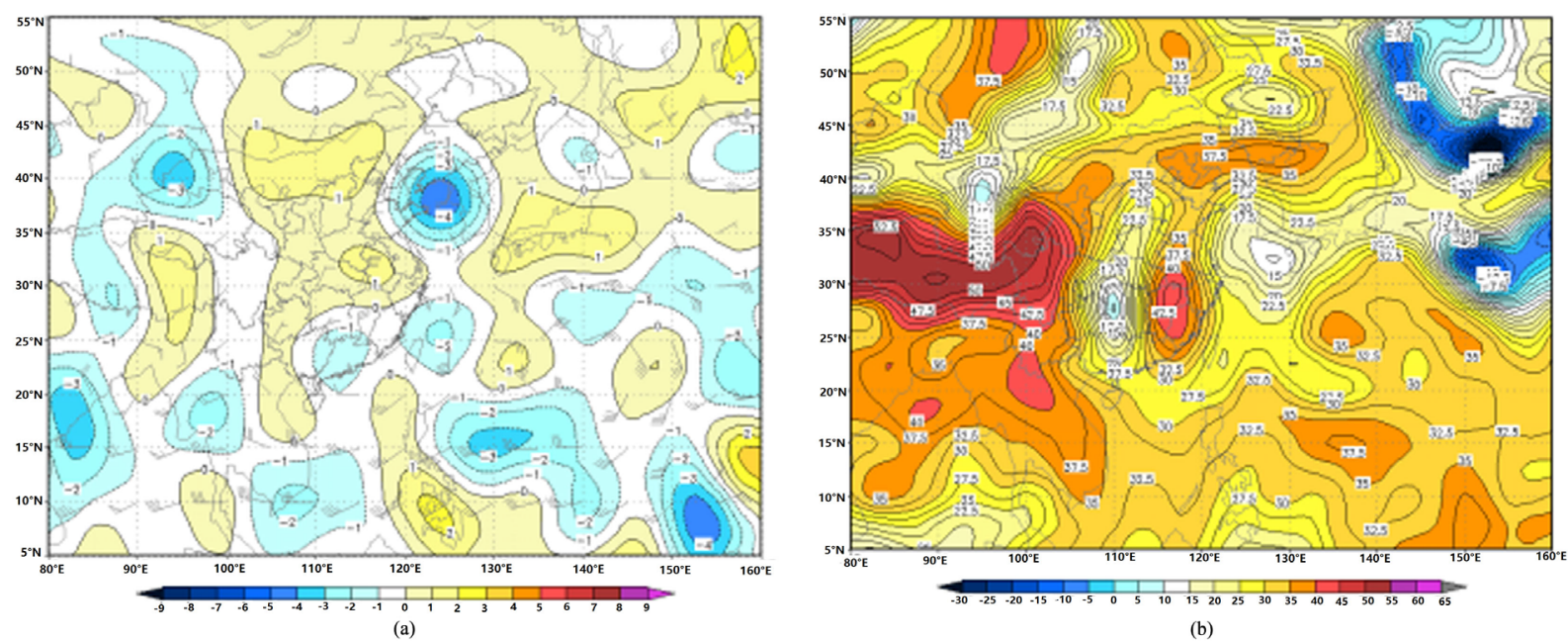

Figure 5. (a) Wind and wind divergence at $850 \mathrm{hPa}$ at 00:00 UTC and (b) K index at 18:00 UTC on August 3, 2012. 
$\mathrm{K}$-Index is a measure of thunderstorm potential in meteorology. According to the National Weather Service, USA, the index harnesses measurements such as vertical temperature lapse rate, moisture content of the lower atmosphere, and the vertical extent of the moist layer [15]. It is generally accepted that k-index greater than $35^{\circ} \mathrm{C}$ is the basic condition for heavy rain events, which is also confirmed over North China in this case (Figure 5(b)).

\section{Conclusions}

Rainstorms are one of the most important meteorological disasters in China, especially heavy storms, and their continued heavy rainfall can lead to frequent natural disasters such as flash floods and debris flows, causing huge losses to people's lives and property. During the typhoon, Dami was in the vicinity of Tianjin in the eastern part of North China and Hebei Province. On August 3, 2012, heavy rainfall occurred in Qinhuangdao, Hebei Province and Tangshan City, Hebei Province.

1) The causes of the torrential rains include the south-facing subtropical high and the south-easterly jet stream around the Sula typhoon, a water vapor and energy belt that allow the Daveilu to maintain long-term water vapor and heat in the eastern part of North China. The structure of the Davidsia caused a strong ascending updraft in the eastern part of North China, with a K-index greater than $35^{\circ} \mathrm{C}$, which provided the impetus for the formation of heavy rainfall.

2) The study also found that the typhoon storm in North China is the result of the interaction between the westerly, subtropical and tropical systems. Subtropical and tropical systems have a clear interaction during this heavy rain.

3) The situation of circulation at $500 \mathrm{hPa}$ before the regional heavy rainstorms and the meridional features of the typhoon at low latitudes are outstanding. At the same time, the typhoon and the cold air in the middle and high latitudes have the characteristics of the opposite movement, that is, the typhoon exists, which is favorable for the cold air in the middle and high latitudes to move eastward or southward.

\section{Acknowledgements}

This work was supported by the Tianjin Municipal Meteorological Administration Doctor's Fund (2017bsjj01) of China.

\section{References}

[1] Wang, Y. (2017) Emergency Response Principles of Typhoon Disaster. Open Journal of Social Sciences, 5, 100-104. https://doi.org/10.4236/jss.2017.51008

[2] Guo, R. and Weng, Y. (2017) Analysis of the Positive Effect from the Typhoon Saomai to the Hydrothermal Environment of Shanghai. Journal of Geoscience and Environment Protection, 5, 221-234. https://doi.org/10.4236/gep.2017.58018

[3] Yu, S. and Subrahmanyam, M. (2017) Typhoon-Induced SST Cooling and Rainfall 
Variations: The Case of Typhoon CHAN-HOM and Nangka. Open Access Library Journal, 4, 1-12.

[4] Peng, S.Q., Zhao, Q.H., Chen, M.D., et al. (2006) Mechanism of Geological Hazard of a Highway Slope in Zhejiang Province. Research of Soil \& Water Conservation, 13, 124-102.

[5] Ding, D. and Li, Y. (2011) A Study on Typhoon-Induced Rainfalls over Beijing: Statistics and Case Analysis. Journal of Meteorological Research, 25, 742-753. https://doi.org/10.1007/s13351-011-0605-7

[6] Ren, Z. (1997) Check of the Forecast of a Rare Rainstorm in South Area of Hebei Province in 1996. Meteorological Monthly, 23, 21-26.

[7] Guo, D.F., Zheng, J. and Ai-Hua, X.U. (2006) Diagnosis Analysis of Structure and Rainstorm of the Typhoon "Bilis" in Jiangxi. Meteorology \& Disaster Reduction Research, 29, 52-59.

[8] Mojgan, G., Mehdi, M. and Reza, B. (2017) The Trend of Changes in Surface Wind in the Indian Ocean, in the Period from 1981 to 2015, Using Reanalysis Data, NCEP/NCAR. Open Journal of Marine Science, 7, 445-457. https://doi.org/10.4236/ojms.2017.74031

[9] Pattanaik, D.R., Mukhopadhyay, B. and Kumar, A. (2012) Monthly Forecast of Indian Southwest Monsoon Rainfall Based on NCEP's Coupled Forecast System. At mospheric and Climate Sciences, 2, 479-491. https://doi.org/10.4236/acs.2012.24042

[10] Zhang, X., Zhang, L., Fu, J. and Zhang, L. (2017) Analysis of Characteristics of the Forecast Jump in the NCEP Ensemble Forecast Products. Atmospheric and Climate Sciences, 7, 151-159. https://doi.org/10.4236/acs.2017.71011

[11] Xiong, X., Deng, W., Hu, J., et al. (2017) Design and Implementation of Real-Time Monitoring and Warning System for Regional Disastrous Weather Based on CIMISS. Meteorological Science \& Technology, 45, 453-459.

[12] Berman, F., Casanova, H., Chien, A., et al. (2005) New Grid Scheduling and Rescheduling Methods in the GrADS Project. International Journal of Parallel Programming, 33, 209-229. https://doi.org/10.1007/s10766-005-3584-4

[13] https://en.wikipedia.org/wiki/Typhoon_Damrey_(2012)

[14] Duan, B., Zhang, W., Liu, H., et al. (2017) The Spatial and Temporal Distributions of Warm Sector Rainfall and Frontal Rainfall for the Torrential Rain Event in Beijing on 21 July 2012. Torrential Rain \& Disasters, 36, 108-117.

[15] https://en.wikipedia.org/wiki/K-index_(meteorology) 